\title{
Immediate postoperative measurement of thyroid-stimulating hormone as an early predictor of remission in thyroid-stimulating hormone-secreting pituitary adenomas
}

\author{
Soo Heon Kim, MD, ${ }^{1}$ Cheol Ryong Ku, MD, PhD, ${ }^{2-4}$ Minkyun Na, MD, PhD, Jihwan Yoo, MD, ${ }^{1}$ \\ Woohyun Kim, MD, ${ }^{1}$ In-Ho Jung, MD, ${ }^{1}$ Kyung Won Kim, MD, ${ }^{2}$ Ju Hyung Moon, MD, ${ }^{1,3,4}$ \\ Daham Kim, MD, PhD, ${ }^{2-4}$ Eun Jig Lee, MD, PhD, ${ }^{2-4}$ Sun Ho Kim, MD, PhD, ${ }^{1,5}$ and \\ Eui Hyun Kim, MD, PhD ${ }^{1,3,4}$
}

\begin{abstract}
'Department of Neurosurgery, Yonsei University College of Medicine, Seoul; ${ }^{2}$ Division of Endocrinology and Metabolism, Department of Internal Medicine, Yonsei University College of Medicine, Seoul; ${ }^{3}$ Pituitary Tumor Center, Severance Hospital, Seoul; ${ }^{4}$ Yonsei Endocrine Research Institute, Yonsei University College of Medicine, Seoul; and ${ }^{5}$ Department of Neurosurgery, Ewha Woman's University College of Medicine, Seoul, Republic of Korea
\end{abstract}

OBJECTIVE Thyroid-stimulating hormone (TSH)-secreting pituitary adenoma (TSHoma) is a rare type of pituitary adenoma; thus, little is known about TSHomas. The purpose of this study was to analyze clinical characteristics and therapeutic outcomes of TSHomas based on a single-center experience. The authors also searched for reliable preoperative and early postoperative factors that could predict long-term endocrinological remission.

METHODS The clinical, radiological, and pathological characteristics and surgical and endocrinological outcomes of 31 consecutive cases of TSHomas that were surgically treated between 2005 and 2017 were reviewed retrospectively. Preoperative factors were evaluated for their ability to predict long-term remission by comparing remission and nonremission groups. TSH and free thyroxine levels were measured at 2, 6, 12, 18, and 24 hours after surgery to determine whether they could predict long-term remission.

RESULTS Gross-total removal of tumor was achieved in 28 patients (90.3\%), and 26 patients (83.9\%) achieved endocrinological remission by surgery alone based on long-term endocrinological follow-up (median 50 months, range 32-81 months). The majority of the tumors were solid (21/31, 67.7\%), and en bloc resection was possible in 16 patients (51.6\%). Larger tumor size and tumor invasion into cavernous sinus and sphenoid sinus were strong predictors of lower rates of endocrinological remission. Immediate postoperative TSH level at 12 hours after surgery was the strongest predictor, with a $0.62 \mu \mathrm{lU} / \mathrm{mL}$ cutoff. Postoperative complications included CSF rhinorrhea in one patient and epistaxis in another patient, who underwent additional surgical treatment for the complications.

CONCLUSIONS Tumor size and extent are major prognostic factors for both extent of resection and endocrinological remission. The consistency of TSHomas was more likely to be solid, which makes extracapsular dissection more feasible. Long-term remission of TSHomas could be predicted even during the early postoperative period.

https://thejns.org/doi/abs/10.3171/2020.1.JNS192787

KEYWORDS hyperthyroidism; pituitary adenoma; remission; thyroid-stimulating hormone; transsphenoidal surgery; pituitary surgery

$\mathrm{T}$ HE incidence of thyroid-stimulating hormone (TSH)-secreting pituitary adenoma (TSHoma) is very low and only represents $0.7 \%-0.94 \%$ of all pituitary adenomas. However, it has been reported that the incidence of TSHoma is rising. ${ }^{10,11}$ Unlike a growth hor- mone $(\mathrm{GH})-$ secreting pituitary adenoma, which results in typical clinical features of acromegaly, TSHoma symptoms are similar to those of hyperthyroidism and are often not striking or prominent; thus, diagnosis of TSHoma is difficult. Moreover, laboratory results for resistant thyroid

ABBREVIATIONS ACTH = adrenocorticotropic hormone; $\mathrm{AUC}=$ area under the ROC curve; $\mathrm{CPFT}=$ combined pituitary function test; FSH = follicle-stimulating hormone; $\mathrm{GH}=$ growth hormone; GTR = gross-total resection; IGF-I = insulin-like growth factor-I; LH = luteinizing hormone; PRL = prolactin; ROC = receiver operating characteristic; $\mathrm{TRH}=$ thyrotropin-releasing hormone; $\mathrm{TSH}=$ thyroid-stimulating hormone; $\mathrm{TSH}_{\mathrm{O}} \mathrm{ma}=\mathrm{TSH}$-secreting pituitary adenoma; $\mathrm{T}_{3}=$ triiodothyronine; $\mathrm{T}_{4}=$ thyroxine . SUBMITTED October 13, 2019. ACCEPTED January 10, 2020

INCLUDE WHEN CITING Published online March 13, 2020; DOI: 10.3171/2020.1.JNS192787. 
hormone syndrome and TSHoma are similar; thus, differential diagnosis is more complicated. Even when the condition of central hyperthyroidism is evident in patients with pituitary adenoma, immunohistochemical investigation of the tumor tissue may show that the tumor is endocrine inactive. ${ }^{1}$ In addition, unlike GH-secreting adenomas, the cutoff TSH value to define remission in patients with TSHoma has not been established-even though Losa et al. reported no TSHoma recurrences in patients whose early postoperative TSH was undetectable during a follow-up of 44 months.?

The purpose of this study was to review surgical outcomes for TSHoma cases treated at a single center and to identify factors associated with remission. Furthermore, we investigated whether immediate postoperative TSH and free thyroxine $\left(\mathrm{T}_{4}\right)$ levels could serve as early predictors of long-term remission.

\section{Methods \\ Patient Population}

The pituitary tumor database registry revealed 1735 patients who underwent transsphenoidal surgery at Yonsei University Severance Hospital between October 2005 and August 2017, but only the patients who were diagnosed endocrinologically, radiologically, and pathologically as having TSHoma were selected. Patients with silent thyrotroph adenoma who were positive for TSH based on immunohistochemical results but whose endocrinological evaluation did not show evidence of central hyperthyroidism were excluded from this study. A total of 31 patients were included in this study and their medical records were reviewed retrospectively. This study was approved by the Institutional Review Board of Severance Hospital, Yonsei University College of Medicine.

\section{Endocrinological Evaluation}

Serum TSH (normal range 0.35-4.94 $\mu \mathrm{IU} / \mathrm{mL}$ ), free $\mathrm{T}_{4}$ (normal range $0.70-1.48 \mathrm{ng} / \mathrm{dL}$ ), and triiodothyronine $\left(\mathrm{T}_{3}\right.$, normal range $0.58-1.59 \mathrm{ng} / \mathrm{mL}$ ) levels were measured. $\mathrm{Pa}-$ tients with normal or high TSH levels and with high free $\mathrm{T}_{4}$ (or $\mathrm{T}_{3}$ ) levels were assumed to have secondary hyperthyroidism. For patients who needed preoperative antithyroid medication, thyroid-related hormones were measured repeatedly until free $T_{4}$ levels were low enough to allow surgical treatment.

Basal hormone tests of the anterior pituitary hormones $\mathrm{GH}$, prolactin (PRL), TSH, follicle-stimulating hormone (FSH), and the free $\alpha$-subunit of the luteinizing hormone (LH) and their target hormones insulin-like growth factor-I (IGF-I), free $\mathrm{T}_{4}$, free $\mathrm{T}_{3}$, testosterone, and estradiol were measured preoperatively and postoperatively. The combined pituitary function test (CPFT) to evaluate anterior pituitary function was performed by injecting $0.1 \mathrm{U} /$ $\mathrm{kg}$ insulin, $500 \mathrm{mg}$ thyrotropin-releasing hormone (TRH), and $100 \mathrm{mg} \mathrm{LH}-$ releasing hormone intravenously. Serum $\mathrm{GH}$, cortisol, adrenocorticotropic hormone (ACTH), LH, FSH, TSH, and PRL were measured after 2 hours. The details of the CPFT have been described previously. ${ }^{6}$ A $50 \%$ increase in TSH or a TSH level of $4 \mathrm{IU} / \mathrm{L}$ was considered a normal response. Abnormal TSH responses or an in- crease in the free $\alpha$-subunit/TSH ratio indicated a potential for TSHoma. ${ }^{12}$ CPFT was not only used to detect the TRH response. After a transsphenoidal surgery, partial or complete hypopituitarism occurs, which requires a preoperative anterior pituitary function evaluation to determine whether hormone replacement is needed and to determine whether postoperative hypopituitarism really occurred.

$\mathrm{A} \mathrm{T}_{3}$ suppression test was performed when it was unclear whether the patient had a TSHoma or a nonfunctioning pituitary adenoma in the presence of secondary hyperthyroidism..$^{12}$ In this test, TSH and free $\mathrm{T}_{4}$ levels were measured before and 48 hours after administration of $300 \mu \mathrm{g}$ tertronin. Insufficient suppression on a $\mathrm{T}_{3}$ suppression test was regarded as strong diagnostic evidence of a TSHoma. TSH and free $\mathrm{T}_{4}$ levels were measured 2, 6, 12, 18, and 24 hours after the operation to determine whether these values could predict postoperative remission. A basal hormone test including TSH and free $\mathrm{T}_{4}$ levels was performed at $1,3,6,12,18$, and 24 months after surgery and then every $6-12$ months thereafter.

\section{Radiological Evaluation}

All patients underwent preoperative dynamic MRI of the sellar region using a 1.5-T system (Signa; General Electric) or a 3-T system (Achieva; Philips). They also underwent MRI 1-2 days after surgery. All adenomas were classified according to a modified Hardy radiological classification scheme: type I was confined entirely within the sella turcica and was $<1 \mathrm{~cm}$; type II extended into the suprasellar space $<1 \mathrm{~cm}$ above the line of the diaphragm; type III extended into the suprasellar area $\geq 1 \mathrm{~cm}$ above the line of the diaphragm or extended into the sphenoid sinus; and type IV invaded the cavernous sinus. The coronal view was used to measure the maximum diameter of each tumor. Tumors with a maximum diameter $<1 \mathrm{~cm}$ were classified as microadenomas and tumors with a maximum diameter $\geq 1 \mathrm{~cm}$ were classified as macroadenomas. Based on the preoperative MRI findings, tumor extensions were described as anteroinferior (extension into the sphenoid sinus with sellar dura and bony destruction), lateral (cavernous sinus invasion), or superior (suprasellar extension with chiasmal compression). Cavernous sinus invasion was verified by intraoperative finding and postoperative MRI, and only tumors with confirmed cavernous sinus invasion were further graded according to the Knosp classification scheme. After tumor removal, the extent of resection was determined by the surgeon based on intraoperative findings and an immediate postoperative MR image. Patients were followed up with MRI annually for the first 2 years and then every 2 years thereafter.

\section{Surgical Procedures and Assessment of Remission}

First, patients with free $\mathrm{T}_{4}$ levels $\geq 2 \mathrm{ng} / \mathrm{dL}$ were medicated with an antithyroid drug (methimazole or propylthiouracil) until their free $\mathrm{T}_{4}$ levels dropped below $2 \mathrm{ng} /$ $\mathrm{dL}$ to restore normal thyroid function before surgery to prevent a postoperative thyroid storm. ${ }^{4}$ The whole procedure was performed using conventional microscopic transsphenoidal surgery. Tumors were approached differently based on their location and size and on the presence 
of invasion into the cavernous sinus or suprasellar space. Intrasellar tumors identified on preoperative MRI were removed completely in all cases. When a tumor invaded the cavernous sinus, we made every effort to achieve total resection. As described in our previous publication, ${ }^{5}$ we classified our patients according to the resection technique: en bloc capsulectomy, fragmented capsulectomy, and piecemeal resection. If a pseudocapsule covered the entire surface of a tumor, en bloc resection was always attempted (en bloc capsulectomy). When pseudocapsule formation was incomplete, the tumor was removed as several fragmented pieces (fragmented capsulectomy). When a tumor showed fragile and soft consistency with a scarcely developed pseudocapsule, the tumor was removed in a piecemeal fashion (piecemeal resection). Pseudocapsules were always removed completely because they can be a major source of tumor recurrence. ${ }^{9}$ With the faintest suspicion of dural invasion, as much as possible of the exposed dura mater was removed. Tumor tissues were evaluated histopathologically by immunohistochemical labeling of anterior pituitary hormones and Ki-67.

Remission was diagnosed when total resection was achieved based on the surgeon's evaluation and immediate postoperative MRI findings and when free $\mathrm{T}_{4}$ and TSH levels normalized for at least 6 months after cessation of the antithyroid drug. If patients were taking thyroid hormone due to a thyroidectomy, remission was identified by a stable, suppressed TSH status even after tapering off the thyroid hormone dose. For patients whose tumors were not completely removed, Gamma Knife surgery was considered.

\section{Statistical Analysis}

The chi-square and Fisher's exact tests were used to identify significant differences between categorical variables. The Mann-Whitney U-test was used to compare continuous variables between groups. We used a paired t-test to determine differences in TSH, free $\mathrm{T}_{4}$, and free $\alpha$-subunit levels before and after treatment with antithyroid medication. Receiver operating characteristic (ROC) curves were constructed to display the sensitivities and specificities of postoperative TSH levels and remission. Logistic regression was used to calculate the probability of surgical remission based on TSH levels at 2, 6, 12, 18, and 24 hours after surgery. The predictive power was also evaluated using the area under the ROC curve (AUC). The AUC was calculated, and the optimum cutoff level was determined by maximized Youden's index. The results were expressed as the mean \pm SD or as a number with a percentage. The DeLong method was used to compare the ROC curves of the TSH levels at 2, 6, 12, 18, and 24 hours after surgery. MedCalc Statistical Software version 18.10 and IBM SPSS version 23 (IBM Corp.) were used for analysis, and $\mathrm{p}$ values $<0.05$ were considered significant.

\section{Results \\ General Outcomes}

A total of 31 patients diagnosed with hormonally active TSHomas based on clinical and neuroimaging findings underwent pituitary surgery at Yonsei University
TABLE 1. Demographic and clinical characteristics of 31 patients with TSHoma

\begin{tabular}{lccc}
\hline \multicolumn{1}{c}{ Characteristic } & $\begin{array}{c}\text { Remission, } \\
n=26\end{array}$ & $\begin{array}{c}\text { Nonremission, } \\
n=5\end{array}$ & p Value \\
\hline Sex & $16(61.5 \%)$ & $2(40 \%)$ & 0.625 \\
\hline Female & $10(38.5 \%)$ & $3(60 \%)$ & \\
\hline Male & $11.5(32-56)$ & $36(28-60)$ & 0.584 \\
\hline Mean age in yrs (range) & & & 0.301 \\
\hline Clinical presentation & $12(46.2 \%)$ & $3(60 \%)$ & \\
\hline $\begin{array}{l}\text { Hyperthyroidism-related } \\
\text { symptoms }\end{array}$ & $5(19.2 \%)$ & 0 & \\
\hline Headache & $1(3.8 \%)$ & 0 & \\
\hline Amenorrhea & $15(57.7 \%)$ & $2(40 \%)$ & 0.636 \\
\hline Goiter & $17(65.4 \%)$ & $3(60 \%)$ & 1.000 \\
\hline Antithyroid medication & & & \\
\hline
\end{tabular}

Severance Hospital between October 2005 and August 2017. These 31 cases of TSHoma represented only $1.7 \%$ of the total number of pituitary adenomas that were surgically treated during the same period. Among these 31 patients, 3 had undergone thyroidectomy before transsphenoidal surgery: 2 patients for thyroid cancer and the other for Graves' disease. Two of them belonged to the nonremission group and the other was endocrinologically cured. The median follow-up period was 50 months (range 32-81 months). Gross-total resection (GTR) of the tumor was achieved in 28 patients (90.3\%). Twenty-six (83.9\%) of the patients achieved remission after surgery, but 5 patients did not. Demographic and clinical characteristics of the 31 patients are summarized in Table 1 . There were no statistically significant differences in the clinical characteristics between the remission group and the nonremission group. Surgery-related complications included a postoperative case of CSF leakage and a case of epistaxis, and both patients underwent additional surgical treatment for the complications. Once remission was judged to have occurred, none of these patients experienced recurrence during follow-up. Three of 5 nonremission patients eventually received Gamma Knife surgery, and radiological tumor control was shown in these 3 patients even though endocrinological remission was achieved in only 2 of them. Of the other 2 nonremission patients, one patient was under observation and the other was lost to follow-up.

\section{Endocrinological Outcomes}

The median preoperative free $\mathrm{T}_{4}, \mathrm{TSH}$, and free $\alpha$-subunit levels were $1.96 \mathrm{ng} / \mathrm{dL}(1.80-2.31 \mathrm{ng} / \mathrm{dL}), 4.17$ $\mu \mathrm{IU} / \mathrm{mL}(3.11-5.43 \mu \mathrm{IU} / \mathrm{mL})$, and $1.73 \mathrm{IU} / \mathrm{L}(0.87-3.21$ $\mathrm{IU} / \mathrm{L})$, respectively. Although there was no statistical significance due to the small number of patients, preoperative hormone levels, especially TSH and free $\alpha$-subunit levels, were higher in the nonremission group than in the remission group (Table 2).

Twenty patients underwent antithyroid treatment before surgery, and this treatment led to a statistically significant decrease in the free $\mathrm{T}_{4}$ level and a significant increase in the TSH level, but the free $\alpha$-subunit level did 
TABLE 2. Preoperative hormone levels in 31 patients with TSHoma

\begin{tabular}{lccc}
\hline $\begin{array}{c}\text { Initial Laboratory } \\
\text { Test }\end{array}$ & Remission, $\mathrm{n}=26$ & $\begin{array}{c}\mathrm{p} \\
\text { Nonremission, } \mathrm{n}=5\end{array}$ & $\begin{array}{c}\mathrm{Value} \\
\text { Val }\end{array}$ \\
\hline${\text { Free } \mathrm{T}_{4}, \mathrm{ng} / \mathrm{dL}^{*}}^{*}$ & $2.15(1.82-2.72)$ & $2.72(2.24-2.98)$ & 0.583 \\
\hline $\mathrm{TSH}, \mu \mathrm{IU} / \mathrm{mL}$ & $4.22(1.29-14.88)$ & $11.86(2.48-32.04)$ & 0.115 \\
\hline $\begin{array}{l}\text { Free, } \alpha \text {-subunit } \\
\text { IU/L }\end{array}$ & $1.91(0.07-4.98)$ & $6.02(0.49-9.50)$ & 0.203 \\
\hline
\end{tabular}

Values are expressed as the mean (range).

* After excluding 3 patients who underwent total thyroidectomy before surgery, the difference in free $T_{4}$ levels was analyzed based on 25 patients with remission and 3 with nonremission.

TABLE 3. Effect of antithyroid medication on hormone levels in 31 patients with TSHoma

\begin{tabular}{|c|c|c|c|}
\hline \multirow[b]{2}{*}{ Laboratory Test } & \multicolumn{2}{|c|}{ Patient Category } & \multirow{2}{*}{$\begin{array}{c}p \\
\text { Value }\end{array}$} \\
\hline & Before Medication & After Medication & \\
\hline Free $T_{4}, \mathrm{ng} / \mathrm{dL}$ & $2.74 \pm 1.21$ & $1.68 \pm 0.46$ & $0.001^{*}$ \\
\hline $\mathrm{TSH}, \mu \mathrm{IU} / \mathrm{mL}$ & $5.28 \pm 3.44$ & $11.16 \pm 9.94$ & $0.012^{*}$ \\
\hline \multirow[t]{2}{*}{$\begin{array}{l}\text { Free } \alpha \text {-subunit, } \\
\text { IU/L }\end{array}$} & $2.77 \pm 2.58$ & $2.58 \pm 2.33$ & 0.485 \\
\hline & Remission, $\mathrm{n}=19$ & Nonremission, $\mathrm{n}=2$ & \\
\hline$\Delta$ free $T_{4}, \mathrm{ng} / \mathrm{dL}$ & $0.61(0.28-1.77)$ & $1.24(0.63-1.84)$ & 0.573 \\
\hline$\Delta$ free $T_{4}$ ratio & $0.25(0.14-0.48)$ & $0.46(0.36-0.57)$ & 0.573 \\
\hline$\Delta \mathrm{TSH}, \mu \mathrm{IU} / \mathrm{mL}$ & $15.4(8.69-22.11)$ & $2.89(0.66-7.87)$ & 0.105 \\
\hline$\Delta \mathrm{TSH}$ ratio & $5.50(2.10-8.92)$ & $0.73(0.19-1.24)$ & $0.047^{*}$ \\
\hline
\end{tabular}

Continuous variables are expressed as the mean $\pm \mathrm{SD}$. Values for remission and nonremission are expressed as absolute values (range) according to the following formulas: $\Delta$ hormone $=$ hormone level before medication - hormone level after medication; $\Delta$ hormone ratio $=$ (hormone level after medication hormone level before medication)/hormone level before medication, absolute value.

* Statistically significant at $p<0.05$.

not change (Table 3). The degree of the decrease in the free $\mathrm{T}_{4}$ level did not differ between the remission and nonremission groups, but the increase in the TSH level was more prominent in the remission group. Rather than an increase in the absolute TSH value, the percent increase in the TSH level after treatment [(hormone level after medication - hormone level before medication)/hormone level before medication] was associated positively with remission.

The outcome of pituitary function was measured in 27 patients in whom a direct comparison between preoperative and postoperative CPFTs was available. Anterior pituitary hormone function was improved in 15 patients (55.6\%), unchanged in 4 (14.8\%), and new hypopituitarism developed in at least 1 axis in 8 patients (29.6\%).

\section{Radiological Findings}

The median tumor size was $1.7 \mathrm{~cm}$ (range $0.07-5.80$ $\mathrm{cm})$. Three patients $(9.7 \%)$ had microadenomas and 28
TABLE 4. Radiological features in 31 patients with TSHoma

\begin{tabular}{lccc}
\hline \multicolumn{1}{c}{ Feature } & Remission, $\mathrm{n}=26$ & $\begin{array}{c}\text { Nonremission, } \\
\mathrm{n}=5\end{array}$ & $\begin{array}{c}\mathrm{p} \\
\text { Value }\end{array}$ \\
\hline $\begin{array}{l}\text { Median tumor size in } \\
\mathrm{cm} \text { (range) }\end{array}$ & $1.70(0.07-3.00)$ & $2.3(2.00-5.80)$ & $0.004^{*}$ \\
\hline Tumor extension & & & \\
\hline \multicolumn{1}{c}{ Cavernous sinus } & $1(3.8 \%)$ & $3(60 \%)$ & $0.008^{*}$ \\
\hline Sphenoid sinus & $3(11.5 \%)$ & $4(80 \%)$ & $0.005^{*}$ \\
\hline Suprasellar & $16(61.5 \%)$ & $4(80 \%)$ & 0.405 \\
\hline Chiasm compression & $8(30.8 \%)$ & $2(40 \%)$ & 1.000 \\
\hline Modified Hardy type & & & $0.006^{*}$ \\
\hline I & $3(11.5 \%)$ & 0 & \\
\hline II & $14(53.9 \%)$ & 0 & \\
\hline III & $8(30.8 \%)$ & $2(40 \%)$ & \\
\hline IV & $1(3.8 \%)$ & $3(60 \%)$ & \\
\hline
\end{tabular}

* Statistically significant at $p<0.05$.

(90.3\%) patients had macroadenomas (Table 4). All 3 patients with microadenomas successfully reached remission states after surgery. Patients with larger tumors had lower probabilities of achieving remission; thus, tumor size was associated with remission $(p=0.004)$.

Tumor extension into the cavernous sinus or the sphenoid sinus through a sellar floor defect also strongly predicted remission. Among the 4 patients with cavernous sinus extension, only 1 patient achieved surgical remission (Knosp class 3), whereas the other 3 patients underwent neither total removal nor endocrinological remission after surgery ( 2 in Knosp class 2 and 1 in Knosp class 4). However, the incidence of a suprasellar extension did not differ between the remission and nonremission groups. The modified Hardy classification showed a difference between the two groups; all of the tumors in the nonremission group were Hardy grades III and IV.

\section{Histopathological Results}

All 31 patients were positive with TSH stain. Among them, GH and PRL stains were positive in 11 patients (35.5\%) and 7 patients (22.6\%), respectively. In 2 of them, GH and PRL were both positive. However, IGF-I or PRL elevation was not evident in any of them. We have identified 16 TSHomas whose immunohistochemistry results were also positive for either GH or PRL. When they were compared to the other 15 patients with tumors positive only for TSH, there were no differences between remission and nonremission groups $(\mathrm{p}=0.165)$ (Table 5). Fifteen patients (48.4\%) had a Ki-67 labeling index $<1 \%$ and only 1 patient had a Ki-67 labeling index $>3 \%$. There was no difference in the Ki-67 labeling index between the remission and nonremission groups.

\section{Surgical Findings and Outcomes}

Surgical findings and outcomes for the 31 patients are described in Table 6. Total removal was achieved for 28 (90.3\%) of the patients. Total removal was achieved for all 26 remission patients and for $2(40 \%)$ of the 5 nonremis- 
TABLE 5. Immunohistochemical results in 31 patients with TSHoma

\begin{tabular}{lccc}
\hline $\begin{array}{c}\text { Immunohistochemical } \\
\text { Finding }\end{array}$ & $\begin{array}{c}\text { Remission, } \\
\mathrm{n}=26\end{array}$ & $\begin{array}{c}\text { Nonremission, } \\
\mathrm{n}=5\end{array}$ & $\begin{array}{c}\mathrm{p} \\
\text { Value }\end{array}$ \\
\hline $\begin{array}{l}\text { Hormone stain } \\
\text { Single; positive for TSH }\end{array}$ & $14(53.8 \%)$ & $1(20.0 \%)$ & 0.165 \\
\hline $\begin{array}{l}\text { Multiple hormones } \\
\text { positive }\end{array}$ & $12(46.2 \%)$ & $4(80.0 \%)$ & \\
\hline$\%$ Ki-67 (range) & $0.5(0.5-1.5)$ & $0.5(0.5-1.0)$ & 0.962 \\
\hline
\end{tabular}

TABLE 6. Surgical findings and outcomes in 31 patients with TSHoma

\begin{tabular}{lrcc}
\hline \multicolumn{1}{c}{ Variable } & $\begin{array}{c}\text { Remission, } \\
n=26\end{array}$ & $\begin{array}{c}\text { Nonremission, } \\
n=5\end{array}$ & p Value \\
\hline Total removal & $26(100 \%)$ & $2(40 \%)$ & $0.002^{*}$ \\
\hline Tumor consistency & & & 0.296 \\
\hline Solid & $19(73.1 \%)$ & $2(40 \%)$ & \\
\hline Soft & $7(26.9 \%)$ & $3(60 \%)$ & \\
\hline Tumor removal method & & & 0.135 \\
\hline En bloc capsulectomy & $15(57.7 \%)$ & $1(20 \%)$ & \\
\hline Fragmented capsulectomy & $5(19.2 \%)$ & $1(20 \%)$ & \\
\hline Piecemeal resection & $6(23.1 \%)$ & $3(60 \%)$ & \\
\hline
\end{tabular}

* Statistically significant at $p<0.05$.

sion patients. Tumor consistency was solid and hard in 21 patients (67.7\%). These tumors were well encased by pseudocapsule, facilitating extracapsular resection, which was described in our previous report. ${ }^{5}$ In the other 10 patients $(32.2 \%)$, the tumors were soft and friable. Overall, tumor removal was performed by capsulectomy in 22 patients (71.0\%) and by piecemeal resection in 9 patients $(29.0 \%)$. En bloc resection was possible in 16 patients $(51.6 \%)$. Total removal of the tumor was the only factor that predicted remission. Although the association was not statistically significant, tumors in the remission group were more likely to have been removed by extracapsular resection than by piecemeal removal (76.9\% vs $23.1 \%$ ).

\section{Early Postoperative TSH Level as a Predictor of Long- Term Remission}

Free $\mathrm{T}_{4}$ levels did not differ significantly between the remission and nonremission groups at any of the postoperative time points (2-24 hours after surgery). However, TSH levels at $6,12,18$, and 24 hours after surgery differed significantly between the remission and nonremission groups (Fig. 1 and Table 7). ROC analysis showed that the AUCs were very high at 2-24 hours after surgery. The maximal AUC was 0.957 at 12 hours after surgery. The optimal TSH cutoff level 12 hours after surgery was $0.62 \mu \mathrm{IU} / \mathrm{mL}$ as determined by Youden's index. With a 0.62 cutoff level, the TSH level 12 hours after surgery reliably predicted long-term remission with $87 \%$ sensitivity
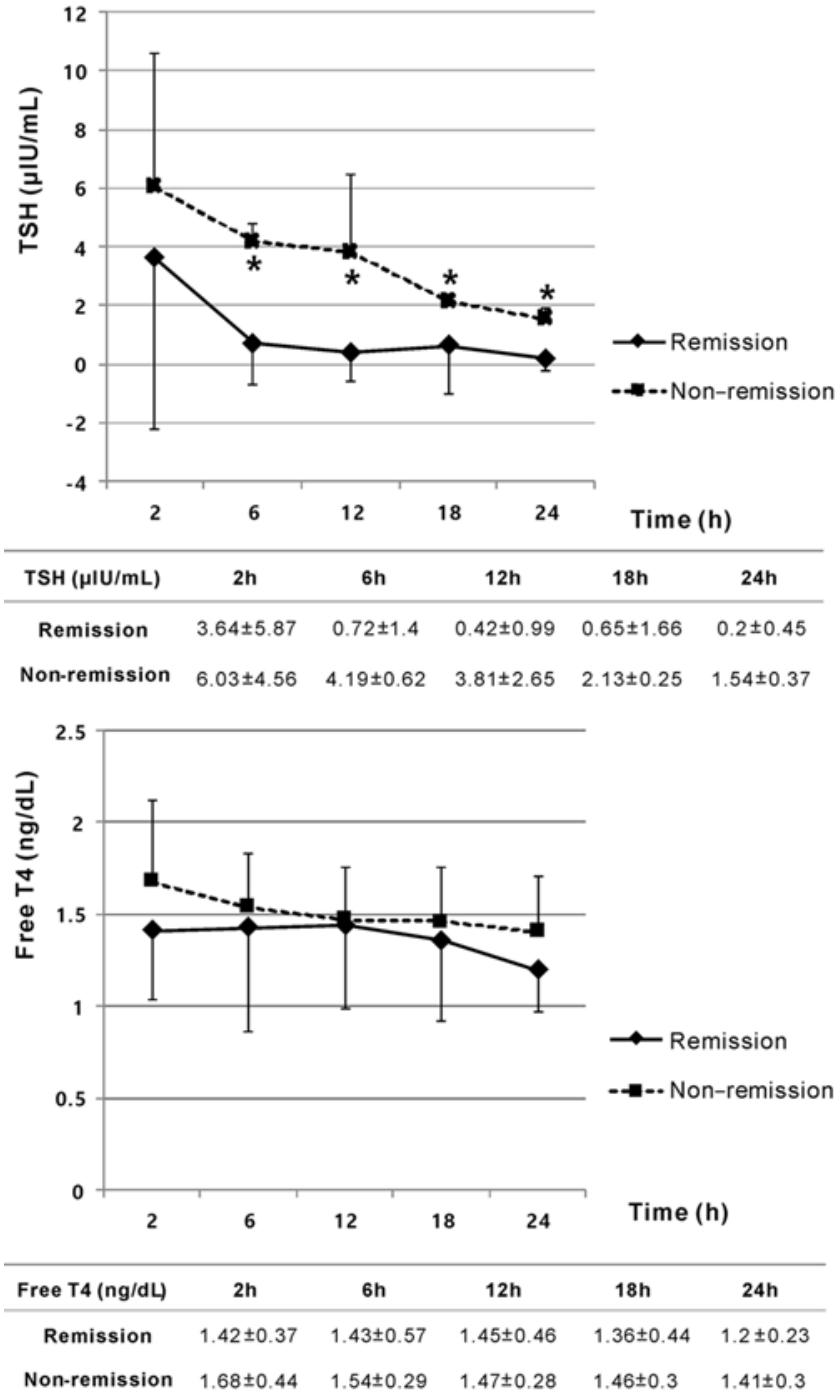

FIG. 1. Comparison of postoperative hormone levels of TSH and free $\mathrm{T}_{4}$. During the immediate postoperative period the TSH levels were much lower in the remission group than in the nonremission group at all time points (upper), whereas free $\mathrm{T}_{4}$ levels were not (lower). They were marked as the mean $\pm S D$. * $p$ value $<0.05$ between remission and nonremission groups.

and $100 \%$ specificity (100\% of positive predictive value and $62.5 \%$ of negative predictive value).

\section{Discussion}

TSHoma is a rare type of pituitary adenoma and a relatively limited number of publications on this lesion are available in the literature when compared with other types of pituitary adenomas, perhaps due to challenges in diagnosing TSHoma. First, hyperthyroidism symptoms are rather vague compared to other types of endocrine-inactive pituitary adenomas. Moreover, TSHoma is not a common cause of hyperthyroidism. In addition, elevated TSH and free $\mathrm{T}_{4}$ levels are not always typical in TSHoma, which makes early diagnosis more difficult. Indeed, the majority 
TABLE 7. Postoperative TSH levels, their optimal cutoff, and AUC

\begin{tabular}{lcccc}
\hline $\begin{array}{c}\text { Time } \\
\text { Postop }\end{array}$ & OR $(95 \% \mathrm{Cl})$ & $\begin{array}{c}\mathrm{p} \\
\text { Value }\end{array}$ & $\begin{array}{c}\text { Optimal } \\
\text { Cutoff, } \\
\mu \mathrm{IU} / \mathrm{mL}\end{array}$ & AUC $(95 \% \mathrm{Cl})$ \\
\hline $2 \mathrm{hrs}$ & $0.913(0.780-1.068)$ & 0.257 & & $0.768(0.585-0.952)$ \\
\hline $6 \mathrm{hrs}$ & $0.508(0.259-0.993)$ & $0.048^{*}$ & 0.86 & $0.928(0.822-1.000)$ \\
\hline $12 \mathrm{hrs}$ & $0.440(0.207-0.934)$ & $0.033^{*}$ & 0.62 & $0.957(0.877-1.000)$ \\
\hline $18 \mathrm{hrs}$ & $0.237(0.063-0.897)$ & $0.034^{*}$ & 0.49 & $0.942(0.850-1.000)$ \\
\hline $24 \mathrm{hrs}$ & $0.080(0.010-0.662)$ & $0.019^{*}$ & 0.39 & $0.942(0.850-1.000)$ \\
\hline
\end{tabular}

* Statistically significant difference $(p<0.05)$ between remission and nonremission groups.

of our cases were misdiagnosed as a primary hyperthyroidism, such as Graves' disease, before the sellar MRI was performed. It has been reported that only $67 \%$ of patients are aware of the symptoms of hyperthyroidism at diagnosis.

Despite a relatively lower number of studies, there is consensus on the management of TSHomas. The extent of resection has been shown to be associated with tumor size and extent. The presence of cavernous sinus invasion is a strong negative prognostic factor for GTR and endocrinological remission, and GTR is always essential for endocrinological remission. ${ }^{13}$ In the meta-analysis of 23 studies by Cossu et al., ${ }^{3}$ only $54.1 \%$ of 536 patients underwent GTR; however, $69.7 \%$ of the patients achieved endocrinological remission. In our small number of cases, the GTR rate was $90.3 \%$ and the endocrinological remission rate was $83.9 \%$. Nevertheless, the incidence of cavernous sinus invasion did not differ between the meta-analysis and our study (30\% vs $25.8 \%$ ), and this supports our conclusion that radical resection is critical for curing TSHomas biochemically. As described in our previous studies, the consistency of the tumors was fairly solid in the majority of cases; thus, en bloc extracapsular tumor resection was more feasible. ${ }^{5}$ Identification of the dissection plane between the pseudocapsule and the normal pituitary glandular tissue is very important for radical tumor removal and safe preservation of pituitary function. We always attempted extracapsular dissection during tumor removal, which may be the reason for the excellent surgical outcomes, including the high GTR rate and the endocrinological remission rate.

Treatment with antithyroid medication, which inhibits the peripheral conversion of $\mathrm{T}_{3}$ to free $\mathrm{T}_{4}$, resulted in a decrease in the free $\mathrm{T}_{4}$ level and an increase in the TSH level. When remission and nonremission groups were compared, we found no difference in the decrease in free $\mathrm{T}_{4}$ levels. However, the decrease in the TSH level in the remission group was 7.5 times higher than in the nonremission group $(\mathrm{p}=0.047)$. Normally, TSH secretion is regulated via negative feedback from thyroid hormone onto the TRH-producing hypothalamic cells and the TSH-secreting anterior pituitary cells. However, in TSHomas, the negative feedback mechanism of thyroid hormone has no effect on TSH production from thyrotroph adenoma cells. ${ }^{12}$ In TSHomas, the mechanism underlying the responsiveness of TSH to antithyroid medication is unknown and requires further studies.

In this study, we hypothesized that immediate postop- erative TSH levels could be used as an early predictor of endocrinological remission. Because the half-life of TSH is merely 1 hour, we speculated that a drop in the TSH level could be observed during the immediate postoperative period if the tumor was completely removed. Indeed, we found that TSH levels between remission and nonremission groups differed during the immediate postoperative period at the 6-, 12-, 18-, and 24-hour time points (Fig. 1 upper, Table 7). To select the most reliable time point and TSH level that shows the highest predictability of remission, we determined the optimal TSH level cutoffs for each time point after surgery, which were $0.86,0.62,0.49$, and $0.39 \mu \mathrm{IU} / \mathrm{mL}$ for $6,12,18$, and 24 hours after surgery, respectively. Comparison of ROC curves using DeLong's method showed no significant differences between the time points. The TSH level 12 hours after surgery was chosen as the most reliable predictor of remission because its AUC was the highest at 0.957. In a clinical setting, an insufficient decrease in the TSH level (TSH $>0.62 \mu \mathrm{IU} /$ $\mathrm{mL}) 12$ hours after surgery indicates that remnants of the tumor are still in the patient, and this necessitates immediate imaging to detect the unexpected remnant. Similarly, Yang et al. reported that TSH levels 3 days and 1 month after surgery were significantly associated with 1 -year postoperative remission. ${ }^{14}$ Unlike TSH, the free $\mathrm{T}_{4}$ level did not differ between the remission and nonremission groups, perhaps because the half-life of free $\mathrm{T}_{4}$ is $5-7$ days and because free $T_{4}$ is mostly bound to protein and converted to $\mathrm{T}_{3}$ in peripheral blood.

Our study has several limitations. First of all, the number of patients was too small, especially in the nonremission group, which made it difficult to have statistical significance. Second, the pulsatile nature of TSH secretion was not taken into consideration when we analyzed the predictive power of immediate postoperative TSH levels for long-term remission. Because it is known that TSH has a circadian rhythm that peaks between 11 PM and 5 $\mathrm{AM},{ }^{8}$ this could have possibly affected the result. Third, methimazole, which was maintained until 2-3 days before transsphenoidal surgery in the majority of cases, might have affected the level of postoperative TSH and free $\mathrm{T}_{4}$. The half-life of methimazole is 4-6 hours; however, its action duration could be approximately 36-72 hours due to its intrathyroidal residence, ${ }^{2}$ which suggests that the possibility that preoperative methimazole affected the change in the immediate postoperative TSH and free $\mathrm{T}_{4}$ is probably quite low. However, we have recognized that this could also be one of the limitations in our study.

\section{Conclusions}

Tumor size and extent are major prognostic factors for both extent of resection and endocrinological remission in surgical treatment for TSHoma. TSHoma, unlike other types of pituitary adenomas, frequently presents with a solid consistency that makes extracapsular dissection more feasible during tumor removal. Long-term remission of TSHoma can be predicted even during the early postoperative period. We determined that a TSH level $<0.62$ $\mu \mathrm{IU} / \mathrm{mL}$ at 12 hours after surgery is a reliable predictor of long-term endocrinological remission. 


\section{Acknowledgments}

This study was funded by the Basic Science Research Program through the NRF of Korea (NRF-2018R1C1B5042687) from the Korean Ministry of Science; ICT and Future Planning (Eui Hyun Kim); and the "Dongwha" Faculty Research Assistance Program of Yonsei University College of Medicine (6-2018-0073) (Eui Hyun Kim)

We thank Juyoon Park, RN, MPH, OCN; Min Kyeong Jang, RN, KOAPN, PhD; Sung Ja Kang, RN; Sujin Ryu, RN; and Yong Jun Jang, RN, for their tremendous effort in performing the endocrinological tests and data acquisition for such a long follow-up duration. We also express our sincere gratitude to Sinae Kim for the statistical advice.

\section{References}

1. Beck-Peccoz P, Brucker-Davis F, Persani L, et al. Thyrotropin-secreting pituitary tumors. Endocr Rev. 1996;17(6):610638.

2. Clark SM, Saade GR, Snodgrass WR, Hankins GD. Pharmacokinetics and pharmacotherapy of thionamides in pregnancy. Ther Drug Monit. 2006;28(4):477-483.

3. Cossu G, Daniel RT, Pierzchala K, et al. Thyrotropin-secreting pituitary adenomas: a systematic review and meta-analysis of postoperative outcomes and management. Pituitary. 2019;22(1):79-88.

4. Dyer MW, Gnagey A, Jones BT, et al. Perianesthetic management of patients with thyroid-stimulating hormonesecreting pituitary adenomas. J Neurosurg Anesthesiol. 2017;29(3):341-346.

5. Kim EH, Ku CR, Lee EJ, Kim SH. Extracapsular en bloc resection in pituitary adenoma surgery. Pituitary. 2015;18(3):397-404.

6. Lee EJ, Ahn JY, Noh T, et al. Tumor tissue identification in the pseudocapsule of pituitary adenoma: should the pseudocapsule be removed for total resection of pituitary adenoma? Neurosurgery. 2009;64(3)(suppl):ons62-ons70.

7. Losa M, Giovanelli M, Persani L, et al. Criteria of cure and follow-up of central hyperthyroidism due to thyrotropinsecreting pituitary adenomas. J Clin Endocrinol Metab. 1996;81(8):3084-3090.

8. Melmed S, Polonsky KS, Larsen PR, Kronenberg HM, eds. Williams Textbook of Endocrinology. 13th ed. Philadelphia: Elsevier; 2016.
9. Oh MC, Kim EH, Kim SH. Coexistence of intracranial aneurysm in 800 patients with surgically confirmed pituitary adenoma. J Neurosurg. 2012;116(5):942-947.

10. Ónnestam L, Berinder K, Burman P, et al. National incidence and prevalence of TSH-secreting pituitary adenomas in Sweden. J Clin Endocrinol Metab. 2013;98(2):626-635.

11. Tjörnstrand A, Gunnarsson K, Evert M, et al. The incidence rate of pituitary adenomas in western Sweden for the period 2001-2011. Eur J Endocrinol. 2014;171(4):519-526.

12. Tjörnstrand A, Nyström HF. Diagnosis of endocrine disease: diagnostic approach to TSH-producing pituitary adenoma. Eur J Endocrinol. 2017;177(4):R183-R197.

13. Yamada S, Fukuhara N, Horiguchi K, et al. Clinicopathological characteristics and therapeutic outcomes in thyrotropinsecreting pituitary adenomas: a single-center study of 90 cases. J Neurosurg. 2014;121(6):1462-1473.

14. Yang YY, Liu H, Hu A, et al. The surgery of thyrotropinsecreting pituitary adenomas and the significance of thyroid stimulating hormone level in follow-up [in Chinese]. Zhonghиа Yi Xиe Za Zhi. 2016;96(47):3825-3828.

\section{Disclosures}

The authors report no conflict of interest concerning the materials or methods used in this study or the findings specified in this paper.

\section{Author Contributions}

Conception and design: EH Kim. Acquisition of data: EH Kim, Soo Heon Kim, Sun Ho Kim. Analysis and interpretation of data: Soo Heon Kim, Ku. Drafting the article: Soo Heon Kim, Ku. Critically revising the article: EH Kim. Reviewed submitted version of manuscript: EH Kim, Ku, Na, Yoo, W Kim, Jung, KW Kim, D Kim, Lee. Approved the final version of the manuscript on behalf of all authors: EH Kim. Administrative/technical/material support: EH Kim, Moon. Study supervision: EH Kim, Sun Ho Kim.

\section{Correspondence}

Eui Hyun Kim: Yonsei University College of Medicine, Seoul, Republic of Korea. euihyunkim@yuhs.ac. 